\title{
Symptom and Comorbidity Burden in Chronic Disease: Comparison of HIV- Infection and Diabetes Mellitus in Aging Patients
}

Eva Wolf', Christian Hoffmann ${ }^{2}$, Knud Schewe ${ }^{2,12}$, Stephan Klauke ${ }^{3,12}$, Robert Baumann ${ }^{4}$, Martin Karwat ${ }^{5}$, Frank Schlote ${ }^{6}$, Franz Mosthaf ${ }^{7}$ Hans Heiken ${ }^{8}$, Axel Baumgarten ${ }^{9}$, Albrecht Ulmer $^{10}$, and Hans Jaeger ${ }^{11,12}$ for the dagnae 50/2010 study group

${ }^{1}$ MUC Research, Munich, Germany

2ICH Study Center, Hamburg, Germany

${ }^{3}$ Infektiologikum Frankfurt, Frankfurt, Germany

${ }^{4}$ Private Practice Dr. R. Baumann, Neuss, Germany

${ }^{5}$ Private Practice Dr. M. Karwat, Munich, Germany

${ }^{6}$ Praxisgemeinschaft Turmstrasse, Berlin, Germany

${ }^{7}$ Private Practice for Hematology, Oncology and Infectious Diseases, Karlsruhe

${ }^{8}$ Praxis Georgstrasse, Hannover, Germany

${ }^{9}$ Medical Center for Infectious Diseases (MIB), Berlin, Germany

${ }^{10}$ Private Practice Dres. Ulmer/Frietsch/Mueller/Roll, Stuttgart, Germany

${ }^{11}$ MVZ Karlsplatz - HIV Research and Clinical Care Centre, Munich, Germany

${ }^{12}$ dagnae e.V., The German Association of Physicians Specialized in HIV Care, Berlin, Germany

\section{Abstract}

Background: Data on the relative contribution of HIV-infection to aging and age-related diseases remains inconclusive, and the total burden of disease has not been compared to other chronic diseases associated with premature aging. The purpose of this study was to investigate aging with HIV-infection and to compare it to aging with diabetes mellitus (DM) type 2 and aging without severe chronic disease.

Methods: This was a prospective multi-center cohort study evaluating differences in the total burden of disease between different groups of older patients ( $\geq 50$ years). HIV-infected patients were compared to HIV-negative patients with DM type 2 and to a control group of patients without severe chronic disease. Physical constitution and activity, symptoms of aging, cardiovascular risk profile and comorbidities were analyzed. Clinical variables and patient questionnaires were assessed during 18 months follow-up.

Results: Among 761 participants (255 HIV, 249 DM, and 257 controls), weakness was most frequently found in HIV-infected patients. The perceived severity of symptoms of aging was significantly higher in patients with HIVinfection or DM than in the control group. Several comorbidities such as renal, neurological and cardiovascular disorders were more common in patients with HIV-infection or DM than in the control group. After adjusting for smoking and non-modifiable risk factors, the prevalence odds of a high cardiovascular risk remained markedly increased for patients with DM and, to a lesser extent, also for patients with HIV-infection. Malignancy incidence rates were highest in HIV-infected patients, followed by patients with DM and lowest in the control group.

Conclusions: This large cohort study in aging patients showed a considerable burden of disease associated with antiretrovirally treated HIV-infection as well as DM when compared to a control population without severe chronic disease - reflecting the need for specific prevention strategies and screening tools.

Keywords: HIV-infection; Aging; Chronic disease; Diabetes mellitus; Comorbidities; Disease burden; Symptoms of aging

\section{Introduction}

The number of people living with HIV/AIDS in the 50-year-plus age group is rising, especially in industrialized nations. With the widespread use of highly active antiretroviral therapy (HAART), physicians and patients are facing new challenges in the treatment and management of age-related comorbidities [1-5]. Several cohort studies showed that HIV-infected patients are at increased risk for individual comorbidities, i.e. for bone [1,3-5], renal [1,6,7], neurocognitive and cardiovascular disorders $[1,8,9]$ as well as non-AIDS-defining malignancies [10]. The relative contribution of HIV-infection and HIV-related factors such as inflammation, immune activation and altered coagulation to the development of different comorbidities in aging individuals is still inconclusive. Other risk factors, life style factors or the use of antiretroviral drugs may contribute to excess morbidity $[2,8,11-17]$.

With this study, we tried to identify the differences in the total burden of disease between HIV-infected patients in comparison to two HIV-negative comparator groups. The first group included patients without any severe chronic or malignant disease, the second included patients with diabetes mellitus type 2, another chronic disease representing a major global cause of premature morbidity and excess mortality [18-20].

The three groups were compared in terms of physical constitution, physical activity, weakness, symptoms of aging, cardiovascular risk profile, comorbidities and concomitant medication.

*Corresponding author: Eva Wolf, Dr. phil., M.P.H., MUC Research, Karlsplatz 8, 80335 Munich, Germany, Tel: +49 89-558-7030; Fax: +498-959-989-353; E-mail: ewo@mucresearch.de

Received September 01, 2015; Accepted November 28, 2015; Published December 03, 2015

Citation: Wolf E, Hoffmann C, Schewe K, Klauke S, Baumann R, et al. (2015) Symptom and Comorbidity Burden in Chronic Disease: Comparison of HIV-Infection and Diabetes Mellitus in Aging Patients. J AIDS Clin Res 6: 527. doi:10.4172/21556113.1000527

Copyright: (c) 2015 Wolf E, et al. This is an open-access article distributed under the terms of the Creative Commons Attribution License, which permits unrestricted use, distribution, and reproduction in any medium, provided the original author and source are credited. 


\section{Methods}

\section{Study design and study population}

$50 / 2010$ (the 50-year-plus age group in 2010) was a noninterventional, multi-center nationwide prospective 18-months cohort study initiated by The German Association of Physicians Specialized in HIV Care (dagnae e.V.) comparing HIV-infected patients with two HIV-negative patient groups, i.e. patients with diabetes mellitus type $2(\mathrm{DM})$ and control patients. Inclusion criteria were an age $\geq 50$ years and the absence of any life-threatening or malignant disease requiring treatment. Additional inclusion criteria for HIV-infected patients were chronic HIV-infection and no acute opportunistic infection at the time of study entry.

Inclusion criteria for the DM group was clinical diagnosis of DM verified by its documentation in the patient file or HbAlc levels $\geq 6.5 \%$, fasting plasma glucose levels $\geq 126 \mathrm{mg} / \mathrm{dL}$ or the use of anti-diabetic drugs.

Inclusion criteria for control patients were the absence of any severe or unstable chronic disease at baseline. Health conditions and comorbidities that did not meet the criteria for exclusion in either study group were hypertension, dyslipidemia, depression, history of heart attack or cerebrovascular event (if more than one year ago) and chronic infection with hepatitis $\mathrm{C}$ or hepatitis $\mathrm{B}$ virus (if diagnosis was obtained more than one year ago). Concomitant hepatitis $\mathrm{C}$ infection requiring treatment was excluded. Patients with a history of intravenous drug use receiving replacement therapy were not excluded.

The recruitment of women was stopped in a group if they exceeded $20 \%$ (according to the gender distribution of the HIV-infected population in Germany).

\section{Regulatory requirements}

Prior to the conduct of the study, approvals of the institutional review boards, i.e. the competent ethics committees, were obtained for all study sites. All subjects had to give written informed consent before inclusion in the study.

\section{Data collection}

Biological, clinical and psychosocial parameters were collected at baseline, months 6,12 and 18. The case report form included sociodemographic variables, HIV-related history, vital signs, body weight, laboratory parameters, relevant comorbidities and conditions, and concomitant medication. At each visit patients had to complete questionnaires including life style factors and symptoms of aging. For the male study population, the Aging Males' Symptoms (AMS) scale was used, a self-reported, 17-item questionnaire including a somatic, a psychological and a sexual subscale. The total AMS score has a range from 17 to 85 ; a total score $\geq 37$ indicates moderate or severe subjectively perceived complaints [21]. Women were interviewed regarding the onset of menopause and related symptoms.

As an accepted indicator of weakness/frailty and health status, grip strength of the dominant hand was measured using a dynamometer (Saehan Dynamometer, model SH5001) [22,23]. The prevalence of weakness was defined as grip strength of $30 \mathrm{~kg}$ or less for males and $18 \mathrm{~kg}$ or less for females [24,25]. Factors associated with weak grip strength were evaluated using logistic regression analysis. Covariables considered were HIV-infection, DM, BMI ( $<20$ versus (vs) $\geq 20 \mathrm{~kg} /$ $\mathrm{m}^{2}$ ), number of documented comorbidities ( $\geq 2$ vs $<2$ ), age ( $\geq 65$ vs $<65$ years), gender and physical activity ( $<2 \mathrm{x}$ vs $\geq 2 \mathrm{x} 45 \mathrm{~min} /$ week). In sensitivity analyses, hepatitis $B$ virus (HBV) and hepatitis $C$ virus
(HCV) infection were included as covariables in the model to adjust for potential confounding.

The Hospital Anxiety and Depression Scale (HADS), a selfscreening questionnaire, was used to assess anxiety and depression. Health-related quality of life was evaluated using the 36-item Short Form Health Survey questionnaire (SF-36). Results will be presented elsewhere.

The 10-year risk for coronary heart disease (CHD) including myocardial infarction or coronary death was calculated using the Framingham risk equation considering age, the presence of diabetes mellitus, smoking, JNC-V blood pressure categories, and NCEP total cholesterol categories [26]. A 10 -year risk $\geq 20 \%$ or a history of CHD were defined as high risk. Multivariate logistic regression analysis adjusting for age categories, diabetes mellitus, a positive family history for CHD and smoking was used to evaluate whether HIV-infection by itself represents an additional risk for CHD. Due to low numbers, patients aged $\geq 80$ years were excluded from this evaluation.

\section{Statistics}

Continuous variables were described as medians with interquartile ranges (IQR). The Mann-Whitney U test and the Kruskal Wallis test were used for comparison of continuous variables between two and more groups. The Wilcoxon signed rank test was used to test for significant changes in continuous variables within groups. Fisher's exact test and the chi ${ }^{2}$ test were used for comparison of frequencies between two and more groups. The McNemar test was used to test for significant changes in frequencies within groups. The $\mathrm{P}$-level for significance was $\mathrm{P}<0.05$ (n.s. = not significant).

\section{Results}

\section{Study population}

The study population consisted of 761 participants including 255 patients with chronic HIV-infection (HIV group), 249 HIV-negative patients with diabetes mellitus type 2 (DM group) and 257 HIV-negative controls, all aged $\geq 50$ years. The study participants were recruited in 37 German clinics between July 2008 and December 2009. The last followup visit was in August 2011.

Socio-demographic characteristics of the study population are shown in Table 1. Twenty-one point two percent of patients were of female gender. Chronic hepatitis B was present in $2.4 \%, 0.8 \%$ and $1.2 \%$ in HIV, DM and control patients while chronic hepatitis C was found in $5.9 \%, 2.0 \%$ and $2.7 \%$, respectively. Replacement therapy in patients with a history of i.v. drug use was used in $2.0 \%, 0.4 \%$ and $2.0 \%$ of HIV, DM or control patients, respectively.

In HIV-infected individuals, the median duration since HIVdiagnosis was 10.8 years (IQR 5.8 - 15.9 years). The most common risks for HIV-transmission were sexual contacts in MSM (men who have sex with men; $59 \%$ ) and heterosexual contacts (21\%); intravenous drug use was rare with $5 \%$ of patients. The vast majority of HIV-infected patients (95.6\%) was on antiretroviral therapy at study entry. Therapy based on NRTI (nucleos/tide reverse transcriptase inhibitor/s) only, NRTI plus PI (protease inhibitor/s), NRTI plus NNRTI (non-nucleoside reverse transcriptase inhibitor/s), or based on $\geq 3$ drug classes was used in $6.7 \%$, $35.2 \%, 39.5 \%$ and $5.5 \%$ of patients, respectively. About one third of patients (30.2\%) had a history of AIDS. The median CD4 T-cell count was $514 / \mu \mathrm{l}$ (IQR $362-698 / \mu \mathrm{l}$ ), the median relative CD4 T-cell count was $26 \%$ (IQR $19-33 \%$ ); $83.5 \%$ of patients had an HIV-RNA level $<50$ copies/mL at study entry. 


\begin{tabular}{|c|c|c|c|c|}
\hline & & \multirow[b]{2}{*}{ HIV-positive group } & \multicolumn{2}{|c|}{ HIV-negative groups } \\
\hline & & & Patients with DM type 2 & Control patients \\
\hline $\mathbf{N}$ & & 255 & 249 & 257 \\
\hline Age (years) & $\begin{array}{l}\text { Median (IQR) } \\
\text { Range }\end{array}$ & $\begin{array}{c}58.1(50.1-65.6) \\
50.1-81.6\end{array}$ & $\begin{array}{c}61.1(56.6-70.4) \\
50.0-88.3\end{array}$ & $\begin{array}{c}58.4(54.3-66.2) \\
50.1-86.7\end{array}$ \\
\hline Gender & Female, N (\%) & $45(17.6 \%)$ & $52(21.9 \%)$ & $64(24.9 \%)$ \\
\hline Country of origin & Germany, \% & $90.9 \%$ & $92.3 \%$ & $89.9 \%$ \\
\hline \multirow[t]{5}{*}{ Employment } & $\begin{array}{l}\text { Full-time/half-time employees or self- } \\
\text { employed, \% }\end{array}$ & $41.8 \%$ & $37.7 \%$ & $50.6 \%$ \\
\hline & Premature retirement, \% & $23.7 \%$ & $12.6 \%$ & $10.7 \%$ \\
\hline & Regular Retirement, \% & $26.5 \%$ & $34.8 \%$ & $26.5 \%$ \\
\hline & Jobless, $\%$ & $5.6 \%$ & $8.5 \%$ & $7.9 \%$ \\
\hline & Other, \% & $2.4 \%$ & $6.5 \%$ & $4.3 \%$ \\
\hline Stable partnership & $\%$ & $47.0 \%$ & $65.3 \%$ & $72.2 \%$ \\
\hline
\end{tabular}

DM denotes diabetes mellitus; for the calculation of percentages, the denominator has been reduced by the number of missings;

Table 1: Socio-demographic characteristics of the study population.

\begin{tabular}{|c|c|c|c|c|c|}
\hline & & \multicolumn{3}{|c|}{ HIV-negative groups } & \multirow[b]{2}{*}{$\begin{array}{l}\text { P-value across } \\
\text { all groups }\end{array}$} \\
\hline & & $\begin{array}{l}\text { HIV-positive } \\
\text { group ( }=255)\end{array}$ & $\begin{array}{l}\text { Patients with DM type } 2 \\
(\mathrm{~N}=249)\end{array}$ & $\begin{array}{l}\text { Control patients } \\
\quad(\mathrm{N}=257)\end{array}$ & \\
\hline \multirow[t]{2}{*}{ BMI (kg/m²), Median (IQR) } & Males & $24.4(22-27)$ & $29.8(26-34)$ & $26.1(24-28)$ & $<0.001^{\wedge}$ \\
\hline & Females & $23.0(21-25)$ & $29.8(26-33)$ & $25.3(23-28)$ & $<0.001^{\wedge}$ \\
\hline \multirow[t]{2}{*}{$\mathrm{BMI}<20 \mathrm{~kg} / \mathrm{m}^{2}(\%)$} & Males & $10.5 \% \dagger$ & $0.5 \%$ & $1.0 \%$ & $<0.001$ \\
\hline & Females & $22.2 \% \dagger$ & $0.0 \%$ & $4.7 \%$ & $<0.001$ \\
\hline \multirow[t]{2}{*}{$\mathrm{BMI}>30 \mathrm{~kg} / \mathrm{m}^{2}(\%)$} & Males & $7.1 \%$ & $47.7 \%$ & $18.2 \%$ & $<0.001^{\wedge}$ \\
\hline & Females & $2.2 \%$ & $48.1 \%$ & $18.8 \%$ & $<0.001^{\wedge \wedge}$ \\
\hline \multirow[t]{2}{*}{ Physical activity (\%) } & None & $33.7 \%$ & $44.2 \%$ & $33.1 \%$ & 0.015 \\
\hline & $\geq 2-3 x /$ week & $58.9 \%$ & $48.2 \%^{\circ}$ & $57.2 \%$ & 0.036 \\
\hline \multirow[t]{2}{*}{ Current smokers (\%) } & Males & $29.5 \%$ & $22.8 \%$ & $25.9 \%$ & 0.308 \\
\hline & Females & $22.2 \%$ & $17.3 \%$ & $21.9 \%$ & 0.489 \\
\hline \multirow[t]{4}{*}{ Alcohol consumption (\%) } & None, males & $17.0 \%$ & $12.8 \%$ & $8.3 \%$ & $0.036^{*}$ \\
\hline & $\geq 2-3 x /$ week, males & $12.6 \%$ & $10.2 \%$ & $19.3 \%$ & $0.029^{*}$ \\
\hline & None, females & $40.9 \%$ & $40.4 \%$ & $23.4 \%$ & $0.079^{*}$ \\
\hline & $\geq 2-3 x /$ week, females & $2.3 \%$ & $7.7 \%$ & $7.8 \%$ & 0.441 \\
\hline \multirow[t]{2}{*}{ Grip strength (kg), median (IQR) } & Males & $41.0(32-46)^{\circ 0}$ & $41.5(35-49)$ & $43.8(34-50)$ & 0.0264 \\
\hline & Females & $23.0(18-30)$ & $23.0(18-28)$ & $24.0(20-28)$ & 0.8861 \\
\hline Weakness $(\%)$ & $\begin{array}{c}\text { Grip strength } \leq 30 \mathrm{~kg} \text { for males, } \\
\leq 18 \mathrm{~kg} \text { for females }\end{array}$ & $22.4 \%^{\circ}$ & $18.0 \%$ & $13.4 \%$ & 0.032 \\
\hline
\end{tabular}

DM denotes diabetes mellitus; for the calculation of percentages, the denominator has been reduced by the number of missings;

$\wedge(\wedge \wedge)$ for all pairwise comparisons: $\mathrm{P} \leq 0.001(\mathrm{P}<0.01)$; $\dagger \mathrm{HIV}$ versus (vs) control or vs DM patients: $\mathrm{P}<0.001$ and $\mathrm{P}<0.001$, respectively. ${ }^{\circ} \mathrm{DM}$ vs $\mathrm{HIV}$ or vs control patients: $\mathrm{P}<0.05$; ${ }^{\circ} \mathrm{HIV}$ vs control or vs DM patients: $\mathrm{P} \leq 0.01$; ${ }^{*} \mathrm{P}<0.05$ for comparison of groups with lowest and highest proportions

Table 2: BMI, physical activity, life style factors, grip strength and weakness at baseline.

\section{Physical constitution, activity and weakness}

Physical constitution, physical activity and weakness at study entry are shown in Table 2. In the HIV group, significantly more patients had a low BMI $<20 \mathrm{~kg} / \mathrm{m}^{2}$ in comparison to the HIV-negative groups $(10.5 \%$ vs $\leq 1 \%)$; this was true for men and females. In contrast, high BMI was most prevalent in the diabetes mellitus group. BMI did not change significantly during follow-up in either group. Physical activity was comparable between the HIV group and the control group (about half of the patients reported physical activity for at least 2 times per week for $\geq 45 \mathrm{~min}$ ), but was lower in the DM group.

In male patients, the median grip strength was significantly lower in the HIV group than in the DM group or in the control group. In women, we did not observe significant differences. Grip strength did not change significantly during the observation period. With increasing age, grip strength declined in all three groups: median grip strength in males/females was $44 / 24 \mathrm{~kg}$ at the age of $50-60$ years, $41 / 25 \mathrm{~kg}$ at the age of $60-70$ years and $32 / 22 \mathrm{~kg}$ at the age of $70-80$, respectively.

Weak grip strength was observed more frequently in HIV-infected patients than in control patients $(22.4 \%$ vs $13.4 \%, \mathrm{P}=0.010)$. This was also true when excluding HBV- and HCV-infected patients $(22.3 \%$ vs $14.0 \%$, respectively). The difference between the HIV group and the DM group (18.0\%) was not significant. Patients with a weak grip strength were generally older than those without (median 65 vs 58 years; $\mathrm{P}<0.001$ ). In HIV-infected patients, weakness was more common in patients with a $\mathrm{BMI}<20 \mathrm{~kg} / \mathrm{m}^{2}(44 \%$ vs $19 \%, \mathrm{P}=0.051)$. Of covariables analyzed, older age (OR 2.7, 95\% CI 1.8-4.0; $\mathrm{P}<0.001)$, low BMI (OR 3.1, 95\% CI 1.5-6.6; $\mathrm{P}=0.003$ ) and HIV-infection (OR 1.7, 95\% CI 1.1- 
2.7; $\mathrm{P}=0.022$ ) were found to be significantly associated with weakness. There was a trend for the association between low physical activity and weakness (OR 1.4, 95\% CI 0.96-2.6; $\mathrm{P}=0.075)$. Adjusting for $\mathrm{HBV}$ - and $\mathrm{HCV}$-infection did not affect the results.

\section{Symptoms of aging}

The Aging Males' Symptoms (AMS) questionnaire was completed by 514 male patients at baseline and 425 patients at month 12 . At baseline, median AMS summary scores were 37.0, 33.3 and 31.0 in HIV, $\mathrm{DM}$ and control groups, respectively. There were significant differences between the HIV and the control group $(\mathrm{P}<0.001)$ and between the DM and the control group $(\mathrm{P}=0.0039)$ but not between the HIV and DM group.

AMS summary scores $\geq 37$ indicating moderate or severe complaints were significantly more prevalent in HIV and DM groups than in the control group. The prevalences were $51 \%$ in the HIV group ( $47 \%$ in patients with HIV-RNA $<50$ copies $/ \mathrm{mL}, 75 \%$ in patients with HIV-RNA $\geq 50$ copies/mL, $\mathrm{P}=0.008), 45 \%$ in the DM group compared to $29 \%$ in the control group (pairwise comparisons with the control group, $\mathrm{P}<0.0001$ and $\mathrm{P}=0.002$, respectively).

HIV-infection (OR 2.2, 95\% CI 1.5-3.5) and diabetes mellitus (OR $1.9,95 \%$ CI 1.2-2.9) were independently associated with a high AMS summary score after adjusting for age categories (60-69, 70-79 vs 50-59 years), high BMI ( $>28 \mathrm{vs} \leq 28 \mathrm{~kg} / \mathrm{m}^{2}$ ) and stable partnership. Adjusting for HBV- and HCV-infection did not affect these associations. Stable partnership (OR 0.6, 95\% CI 0.4-0.8) was also associated with a lower AMS score. By month 12, there was a small but significant increase in AMS summary score of +2 points in each group.

In women, the onset of menopause was similar across the three patient groups. Median age was 50.2 years in HIV-infected women, 50.4 years in women with DM and 51.4 years in the control female patient group (Kaplan-Meier analysis, $\mathrm{P}=0.6305$ ).

\section{Cardiovascular risk factors and risk for coronary heart disease (CHD)}

In total, 566 patients had complete data for calculation of CHD risk at the baseline visit (204 HIV, $196 \mathrm{DM}$, and 166 control patients). Among the three groups, $39.7 \%, 58.7 \%$ and $26.5 \%$ were at high risk for CHD, respectively (Figure 1). History of CHD and low plasma HDL (high density lipoprotein) levels were significantly more frequent in the HIV and DM groups than in the control group. In contrast, HIV and control patients had significantly higher total cholesterol and LDL (high density lipoprotein) levels than DM patients who were significantly more frequently on lipid lowering drugs (Table 3). Logistic regression analysis adjusting for gender, age categories, DM, smoking and positive family history for $\mathrm{CHD}$ showed that HIV-infection remained independently associated with high CHD risk (OR 1.6, 95\% CI 1.0-2.5, $\mathrm{P}=0.046$, Table 4).

\section{Comorbidities, malignancies and other clinical manifestations}

The prevalence of comorbidities or other medical disorders at baseline was highest in the DM group, followed by the HIV group. At least two comorbidities or other medical disorders were documented in $76.3 \%$ of the DM group, in $67.8 \%$ of the HIV group (70\% in patients with HIV-RNA $<50$ copies/mL, $63 \%$ in patients with HIV-RNA $\geq 50$ copies $/ \mathrm{mL})$ and in $59.1 \%$ of the control group $(\mathrm{P}<0.001)(76.0 \%, 67.1 \%$ and $57.9 \%$, respectively, when excluding HBV- and HCV-infection). Pairwise comparisons showed significant differences between groups. For certain comorbidities, we observed significantly different prevalences in the three groups, with post-hoc tests showing significantly higher prevalences in HIV-infected patients than in control patients,

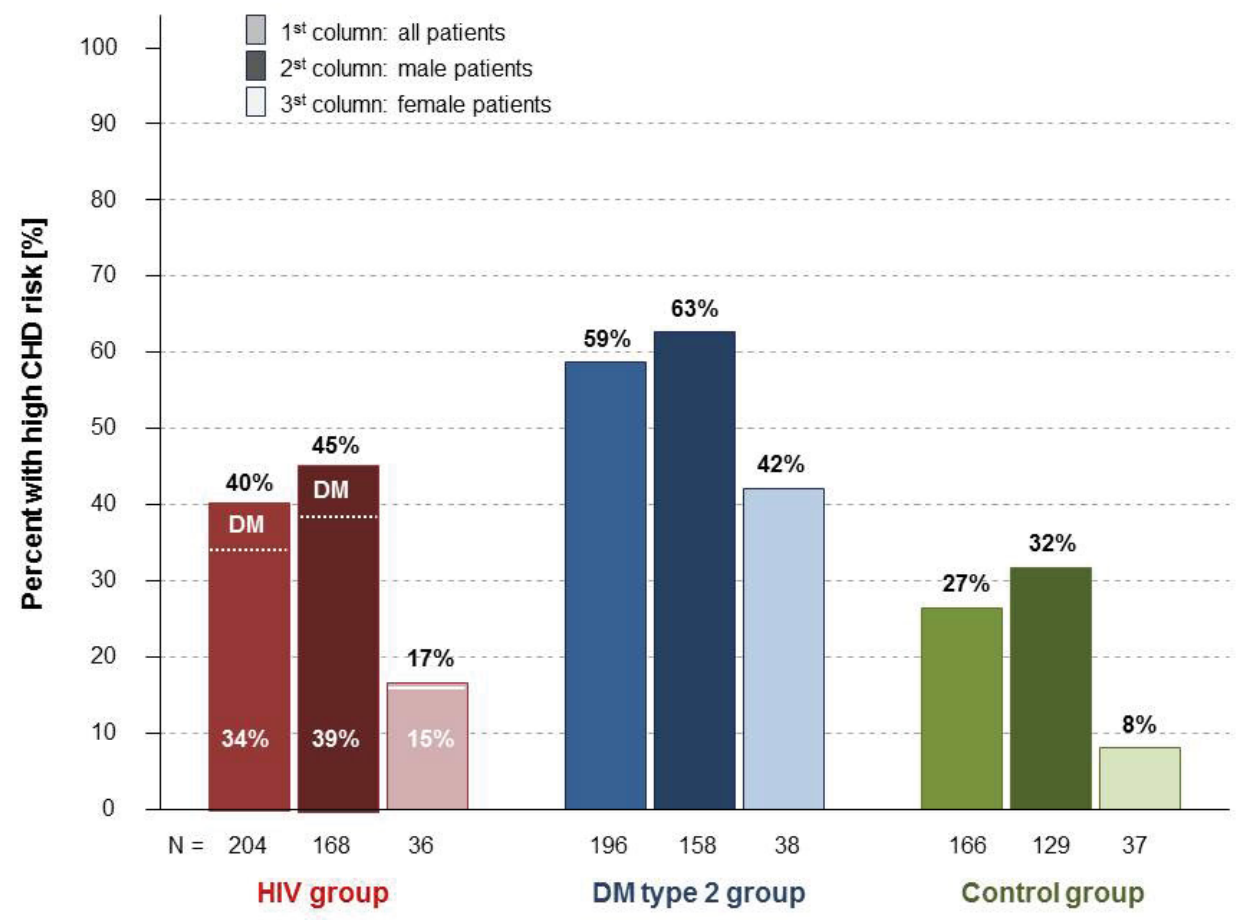

Figure 1: Percentage with high CHD risk in the three patient groups, i.e. HIV, DM type 2 and control patients, overall and stratified by gender. CHD denotes coronary heart disease, DM denotes diabetes mellitus. Pairwise comparisons showed significant differences between all subgroups (P<0.001; except HIV-positive versus HIVnegative females). Since there was a small fraction of HIV-infected patients with DM, the percentages in the bars refer to the HIV group without DM. 


\begin{tabular}{|c|c|c|c|c|}
\hline & \multirow[b]{2}{*}{$\begin{array}{l}\text { HIV-positive patients } \\
(\mathrm{N}=204)\end{array}$} & \multicolumn{2}{|c|}{ HIV-negative groups } & \multirow[b]{2}{*}{$\begin{array}{l}\text { P-value across all } \\
\text { groups }\end{array}$} \\
\hline & & $\begin{array}{l}\text { Patients with DM type } 2 \\
\text { (N=196) }\end{array}$ & $\begin{array}{l}\text { Control patients } \\
\quad(\mathrm{N}=166)\end{array}$ & \\
\hline LDL $^{*}$ cholesterol $\geq 160 \mathrm{mg} / \mathrm{dL}(\%)$ & $21.1 \%$ & $13.0 \%^{\circ}$ & $27.0 \%$ & 0.004 \\
\hline $\begin{array}{l}\text { Low HDL* cholesterol (\%) } \\
\text { (<35 mg/dL in males, } \\
\quad<45 \mathrm{mg} / \mathrm{dL} \text { in females) }\end{array}$ & $20.1 \%$ & $17.9 \%$ & $7.8 \%{ }^{\circ 0}$ & 0.003 \\
\hline Total cholesterol $\geq 240$ mg/dL (\%) & $27.5 \%$ & $12.8 \% \ddagger$ & $34.3 \%$ & $<0.001$ \\
\hline Triglycerides $\geq 200 \mathrm{mg} / \mathrm{dL}$ (\%) & $35.0 \%$ & $32.8 \%$ & $26.7 \%$ & 0.219 \\
\hline Using lipid lowering drugs (\%) & $19.2 \%$ & $40.5 \% \ddagger$ & $18.7 \%$ & $<0.001$ \\
\hline Hypertension stages II-IV ${ }^{\star *}(\%)$ & $15.7 \%$ & $6.6 \% \dagger$ & $13.3 \%$ & 0.016 \\
\hline Smokers (\%) & $28.9 \%$ & $21.9 \%$ & $25.9 \%$ & 0.277 \\
\hline Diabetes mellitus (\%) & $11.3 \%$ & $100.0 \%$ & $0.0 \%$ & - \\
\hline History of MI or documented cardiovascular disease (\%) & $20.1 \%$ & $21.9 \%$ & $9.0 \% \sim$ & 0.003 \\
\hline
\end{tabular}

DM denotes diabetes mellitus, vs versus; *LDL, low density lipoprotein; HDL, high density lipoprotein; **based on JNC-V blood pressure categories [34]; ${ }^{\circ} \mathrm{DM}$ vs HIV or vs control patients: $\mathrm{P}=0.05$ and $\mathrm{P}=0.001$, respectively; ${ }^{\circ}{ }^{\circ}$ Control vs HIV or vs DM patients: $\mathrm{P}<0.01$; $\ddagger \mathrm{DM}$ type 2 vs HIV or vs control patients: $\mathrm{P}<0.001$; $\dagger \mathrm{DM}$ vs HIV or vs control patients: $\mathrm{P}<0.01$ and $\mathrm{P}<0.05$, respectively; ${ }^{2}$ Control vs HIV or vs DM patients: $\mathrm{P}<0.01$;

Table 3: Distribution of cardiovascular risk factors at baseline (in patients with complete data in all variables used for calculation of cardiovascular risk).

\begin{tabular}{|l|c|c|c|}
\hline & $\begin{array}{c}\text { OR for high } \\
\text { CDH risk }\end{array}$ & $\mathbf{9 5 \%}$ Cl & P-value \\
\hline HIV-infection vs no HIV-infection & 1.60 & $1.01-2.53$ & 0.046 \\
\hline DM vs no DM & 4.06 & $2.57-6.41$ & $<0.001$ \\
\hline Female vs male gender & 0.18 & $0.10-0.33$ & $<0.001$ \\
\hline Age 60-69 vs 50-59 years & 3.53 & $2.21-5.63$ & $<0.001$ \\
\hline Age 70-79 vs 50-59 years & 6.07 & $3.28-11.23$ & $<0.001$ \\
\hline Smoker vs non-smoker & 3.23 & $1.92-5.53$ & $<0.001$ \\
\hline Former smoker vs non-smoker & 1.15 & $0.73-1.83$ & 0.533 \\
\hline Positive CHD family history, yes vs no & 1.96 & $1.20-3.20$ & 0.007 \\
\hline Pos. CHD family history, unknown vs no & 1.44 & $0.80-2.60$ & 0.217 \\
\hline
\end{tabular}

OR denotes odds ratio, $\mathrm{CHD}$ coronary heart disease, $\mathrm{Cl}$ confidence interval, vs versus, DM diabetes mellitus; A 10 -year $\mathrm{CHD}$ risk $\geq 20 \%$ or a history of $\mathrm{CHD}$ were defined as high CHD risk.

Table 4: Contribution of HIV-infection to high CHD risk adjusted for age, sex, diabetes mellitus type 2 (DM), smoking, and positive family history.

but usually not significantly different from DM patients, i.e. renal disorders (HIV 9.4\%, DM 13.3\%, controls 3.1\%, $\mathrm{P}<0.01$ for global and pairwise tests, neurological disorders (HIV 14.9\%, DM 14.1\%, controls $4.7 \%, \mathrm{P}<0.001$ ) or history of myocardial infarction (HIV $12.9 \%, \mathrm{DM}$ $14.5 \%$, controls $5.5 \%, \mathrm{P}<0.01$ ). These prevalences were similar when excluding $\mathrm{HBV}$ - and $\mathrm{HCV}$-infection. During the observation time of 18 months, incident malignancies were reported in $10 \mathrm{HIV}$-infected individuals (all non-AIDS defining), in 6 patients of the DM group and in none of the control patients. Incidence rates per 100 person years (PY) were 2.6 in HIV-infected patients (95\% CI 1.2-4.7), 1.7 in the DM group (95\% CI 0.6-3.6), and 0 in the control group (95\% CI 0-1.0). The difference between HIV-infected patients and control patients was significant $(\mathrm{P}<0.001)$, as was the difference between $\mathrm{DM}$ and control patients $(\mathrm{P}=0.015)$. The corresponding relative incidence rates were significantly different from 1 . The lower $95 \%$ confidence interval limits were 2.1 and 1.2 , respectively.

\section{Concomitant medication other than antiretroviral HIV- treatment}

At study entry, the use of concomitant medication in the HIV, DM and control groups was as follows: antihypertensive agents were used in $29.1 \%, 75.4 \%$, and $43.6 \%$ of patients, anticoagulants/antiplatelet drugs (i.e. heparin, phenprocoumon, clopidogrel or acetylsalicylic acid) in $17.7 \%, 33.3 \%$, and $17.1 \%$, lipid lowering drugs in $18.9 \%, 38.7 \%$, and $17.1 \%$, psychotropic drugs in $13.7 \%, 6.8 \%$, and $4.7 \%$, and analgesics in $14.7 \%, 17.3 \%$, and $12.1 \%$, respectively.

\section{Discussion}

This large cohort study is the first to our knowledge to evaluate health conditions and the disease burden in aging HIV-infected patients in comparison to patients with another age-affected condition, diabetes mellitus type 2 and to individuals without any severe chronic disease. HIV-infection was associated with a higher burden of comorbidity, i.e. cardiovascular diseases and malignancies, when compared to patients without severe chronic disease. However, the overall prevalence of all comorbidities and other medical disorders was highest in patients with DM. For certain comorbidities including renal disorders, neurological disorders or history of myocardial infarction, HIV-infected patients were comparably affected. The calculated risk of coronary heart disease was significantly higher in HIV-infected patients (of whom 96\% received antiretroviral treatment) than in HIV-negative controls without chronic disease. However, the excess risk attributed to HIVinfection was lower than that attributed to diabetes mellitus type 2. Our results are in concordance with a systematic review including a metaanalysis and a large cohort study showing that people living with HIV are at increased risk of cardiovascular disease beyond that explained by cardiovascular risk factors $[27,28]$.

The frequency and the burden of symptoms as assessed by the Aging Males' Symptoms (AMS) scale were comparable between HIV and DM patients. Both groups had significantly higher AMS summary scores than the control group. High symptoms scores were even more common in HIV-infected patients with detectable plasma viremia than in patients with viral suppression to $<50$ HIV-RNA copies/ $\mathrm{mL}$. Symptoms of aging included psychological, somatic and sexual complaints.

Weakness, defined as low grip strength, was more prevalent in HIV-infected individuals than in the two HIV-negative groups. Grip strength is widely used as an indicator of physical functioning and is considered as an independent predictor of morbidity and mortality $[23,29,30]$. After adjusting for age, DM, BMI, and physical activity, the association between weakness and HIV-infection remained significant.

The use of concomitant drugs for the treatment of disorders which are often associated with DM was much higher in the DM group than in the two other groups, i.e. the use of antihypertensive agents, lipid lowering drugs and anticoagulants. Interestingly, despite a higher cardiovascular risk in HIV-infected patients in comparison to control patients, the use of antihypertensive drugs was less common in HIV- 
infected patients, and the use of lipid lowering drugs was comparable between HIV-infected and control patients. The use of psychotropic drugs was higher in HIV-infected patients than in the HIV-negative groups.

Although the incidence of malignancies was small during the 18-month follow-up, we observed a significantly higher incidence of non-AIDS-defining malignancies (NADM) in the HIV-infected group than in the control group. These findings are in concordance with data showing a higher incidence of NADM in HIV-infected persons in the HAART era than in the general population, adjusted for age, race, and gender [31,32]. Based on nationwide cohort data, the incidence of cancer among HIV-infected patients in France was 1.4 per 100 person years for the year 2006, with NADM representing $68 \%$ of cases and including a large variety of entities. The relative risk for HIV-infected patients when compared to the general population in France was estimated to be 3.5 for men and 3.6 for women; it was particularly elevated in younger patients [33]. In our study, the incidence of malignancies was at least 2.1 times higher in HIV-infected patients than in control patients (lower limit of the $95 \%$ confidence interval); however, the observed difference in NADM incidence between HIV-infected patients and control patients may not only be attributed to HIV-infection but also to individual life style factors such as smoking or alcohol consumption.

This study has several limitations. Since this was a cohort study, patients were not evenly distributed with respect to cofactors associated with the outcomes of interest. However, the presence of certain cofactors may be attributed to the chronic disease itself or - in case of life style factors - may be attributed to the specific patient group. Therefore an even distribution of covariables may not be desirable as it would not have reflected the specific patient populations seen in clinical routine and would hence not have been appropriate for evaluating the disease burden in these populations. Gender and age distribution were brought into line during recruitment of patient groups (using frequency matching). For estimating associations between outcomes of interest and HIV-infection or diabetes mellitus, confounding was minimized by either stratification of analyses or by multivariable analyses.

One strength of this study lies in the majority of HIV-positive and HIV-negative patients seeking care at the same centers and therefore receiving similar screening methods, therapeutic options and treatment of comorbidities. Although the sample size was large, the study was not powered to detect differences in incident comorbidities. Apart from incident malignancies (the presence of which was excluded at baseline), we focused on prevalent diseases and disorders and were able to detect specific differences between groups. Of note, we did not adjust the level of significance for multiple testing and some outcomes only showed a weak association with HIV-infection. Concerning the DM group, factors associated with clinical outcomes - such as the duration of the disease and the indication for treatment - were not part of the assessment. Therefore, the DM group might have been a very heterogeneous group.

We were able to describe the burden of disease in three aging patient groups under medical treatment or medical observation. Aging antiretrovirally treated HIV-infected patients had a higher burden of comorbidity and symptoms than controls without severe chronic disease, but not than HIV-negative patients with diabetes mellitus. We hence emphasize the need for prevention strategies and good screening tools with regard to cardiovascular, renal, neurologic and malignant diseases in this patient population.

\section{Acknowledgements}

\section{Participating centres - The 50/2010 Study Group}

Dr. Baumann, Neuss; Dres. Baumgarten/Dupke/Carganico, Berlin Mannheimer Onkologie Praxis (Dres. Brust/Schuster/Ploeger/Hensel), Mannheim CIM - Centre for interdisciplinary medicine (Dres. Busch/Christensen), Muenster; Dres. Denger/Sammler, Friedrichsthal; Dr. Dix, Konstanz; Dres. Friese/Czeke Giessen; Dres. Gippert/Hartmann, Muenster; Dr. Gospodinov, Saarbruecken HIV Center Frankfurt (Dr. Haberl); Dres. Hanhoff/Fussen, Geilenkirchen; Dres. Hintsche/Klausen, Berlin; ICH Study Centre (Dres. Hoffmann/Hansen), Hamburg; MVZ Karlsplatz (Dres. Jaeger/Jaegel-Guedes), Munich; Dr. Karwat, Munich; Dres. Koeppe/Kreckel, Berlin; Infektiologikum Frankfurt-Sachsenhausen (Dres Knecht/Klauke); Praxis Georgstrasse (Dres. Kuhlmann/Holm/Heiken), Hannover; Dr. Mauruschat, Wuppertal; Aerzteforum Seestraße (Dres. Mayr/Schmidt), Berlin Dr. Meurer, Munich; Private Practice for Hematology, Oncology and Infectious Diseases (Dres. Mosthaf, Procaccianti, Zutavern-Bechtold), Karlsruhe; Isarpraxis (Dres. Pauli/Becker), Munich; ifi - Institute for Interdisciplinary Infectiology (Dres. Plettenberg/Stoehr/Olah/Sabranski/Unger), Hamburg; Dres. Rausch/ Freiwald, Berlin; Dres. Reith/Gottstein, Duesseldorf; Dr. Schappert, Mainz Praxisgemeinschaft Turmstrasse (Dres. Schlote/Schuler/Lauenroth-Mai), Berlin Dr. Schoelzel, Troisdorf; Dres. Schranz/Fischer, Berlin; Dr. Stuendel, Munich; Dres Ulmer/Frietsch/Mueller/Roll, Stuttgart; Dr. Usadel, Freiburg; Dr. Wuensche, Berlin; Dr. Zebhauser, Munich.

Study management, data management, statistical analysis and support in medical writing

Dr. B. Mueck, Munich, Dr. C. Koegl, Munich, Dr. S. Preis, Munich, A. Balogh, Munich, and N. Hanhoff, Berlin.

\section{Funding/Support}

The study was financially supported by AbbVie (formerly Abbott), Boehringe Ingelheim, Gilead Sciences, GlaxoSmithKline, MSD Sharp \& Dohme and JanssenCilag (formerly Tibotec).

\section{References}

1. Guaraldi G, Orlando G, Zona S, Menozzi M, Carli F, et al. (2011) Premature age-related comorbidities among HIV-infected persons compared with the general population. Clin Infect Dis 53: 1120-1126.

2. Heaton RK, Clifford DB, Franklin DR Jr, Woods SP, Ake C, et al. (2010) HIVassociated neurocognitive disorders persist in the era of potent antiretroviral therapy: CHARTER Study. Neurology 75: 2087-2096.

3. Negredo E, Domingo P, Ferrer E, Estrada V, Curran A, et al. (2014) Peak bone mass in young HIV-infected patients compared with healthy controls. J Acquir Immune Defic Syndr 65: 207-212.

4. Prior J, Burdge D, Maan E, Milner R, Hankins C, et al. (2007) Fragility fractures and bone mineral density in HIV positive women: a case-control populationbased study. Osteoporos Int 18: 1345-1353.

5. Young B, Dao CN, Buchacz K, Baker R, Brooks JT; HIV Outpatient Study (HOPS) Investigators (2011) Increased rates of bone fracture among HIVinfected persons in the HIV Outpatient Study (HOPS) compared with the US general population, 2000-2006. Clin Infect Dis 52: 1061-1068.

6. Overton ET, Nurutdinova D, Freeman J, Seyfried W, Mondy KE (2009) Factors associated with renal dysfunction within an urban HIV-infected cohort in the era of highly active antiretroviral therapy. HIV Med 10: 343-350.

7. Rasch MG, Engsig FN, Feldt-Rasmussen B, Kirk O, Kronborg G, et al. (2012) Renal function and incidence of chronic kidney disease in HIV patients: a Danish cohort study. Scand J Infect Dis 44: 689-696.

8. Islam FM, Wu J, Jansson J, Wilson DP (2012) Relative risk of cardiovascular disease among people living with HIV: a systematic review and meta-analysis. HIV Med 13: 453-468.

9. Heaton RK, Franklin DR, Ellis RJ, McCutchan JA, Letendre SL, et al. (2011) HIV-associated neurocognitive disorders before and during the era of combination antiretroviral therapy: differences in rates, nature, and predictors. J Neurovirol 17: 3-16.

10. Calabresi A, Ferraresi A, Festa A, Scarcella C, Donato F, et al. (2013) Incidence of AIDS-defining cancers and virus-related and non-virus-related non-AIDSdefining cancers among HIV-infected patients compared with the general population in a large health district of Northern Italy, 1999-2009. HIV Med 14: 481-490.

11. Worm SW, Sabin C, Weber R, Reiss P, El-Sadr W, et al. (2010) Risk of 
Citation: Wolf E, Hoffmann C, Schewe K, Klauke S, Baumann R, et al. (2015) Symptom and Comorbidity Burden in Chronic Disease: Comparison of HIV-Infection and Diabetes Mellitus in Aging Patients. J AIDS Clin Res 6: 527. doi:10.4172/2155-6113.1000527

myocardial infarction in patients with HIV infection exposed to specific individual antiretroviral drugs from the 3 major drug classes: the data collection on adverse events of anti-HIV drugs (D:A:D) study. J Infect Dis 201: 318-330.

12. Law MG, Friis-Moller N, El-Sadr WM, Weber R, Reiss P, et al. (2006) The use of the Framingham equation to predict myocardial infarctions in HIV-infected patients: comparison with observed events in the D:A:D Study. HIV Med 7: 218-230.

13. Friis-Møller N, Thiébaut R, Reiss $P$, Weber R, Monforte AD, et al. (2010) Predicting the risk of cardiovascular disease in HIV-infected patients: the data collection on adverse effects of anti-HIV drugs study. Eur J Cardiovasc Prev Rehabil 17: 491-501.

14. Kaplan RC, Landay AL, Hodis HN, Gange SJ, Norris PJ, et al. (2012) Potential cardiovascular disease risk markers among HIV-infected women initiating antiretroviral treatment. J Acquir Immune Defic Syndr 60: 359-368.

15. Hsue PY, Deeks SG, Hunt PW (2012) Immunologic basis of cardiovascular disease in HIV-infected adults. J Infect Dis 205 Suppl 3: S375-382.

16. Sabin CA, Worm SW (2008) Conventional cardiovascular risk factors in HIV infection: how conventional are they? Curr Opin HIV AIDS 3: 214-219.

17. Armah KA, McGinnis K, Baker J, Gibert C, Butt AA, et al. (2012) HIV status, burden of comorbid disease, and biomarkers of inflammation, altered coagulation, and monocyte activation. Clin Infect Dis 55: 126-136.

18. Ott A, Stolk RP, van Harskamp F, Pols HA, Hofman A, et al. (1999) Diabetes mellitus and the risk of dementia: The Rotterdam Study. Neurology 53: 19371942.

19. Stewart R, Liolitsa D (1999) Type 2 diabetes mellitus, cognitive impairment and dementia. Diabet Med 16: 93-112.

20. van Dieren S, Beulens JW, van der Schouw YT, Grobbee DE, Neal B (2010) The global burden of diabetes and its complications: an emerging pandemic. Eur J Cardiovasc Prev Rehabil 17 Suppl 1: S3-8.

21. Heinemann LAJ, Zimmermann T, Vermeulen A, Thiel C (1999) A New 'Aging Male's Symptoms' (AMS) Rating Scale. The Aging Male 2: 105-114.

22. Danon-Hersch N, Rodondi N, Spagnoli J, Santos-Eggimann B (2012) Prefrailty and chronic morbidity in the youngest old: an insight from the Lausanne cohort Lc65+. J Am Geriatr Soc 60: 1687-1694.

23. Rantanen T, Harris T, Leveille SG, Visser M, Foley D, et al. (2000) Muscle strength and body mass index as long-term predictors of mortality in initially healthy men. J Gerontol A Biol Sci Med Sci 55: M168-173.
24. Fried LP, Tangen CM, Walston J, Newman AB, Hirsch C, et al. (2001) Frailty in older adults: evidence for a phenotype. J Gerontol A Biol Sci Med Sci 56: M146-156.

25. Sallinen J, Stenholm S, Rantanen T, Heliövaara M, Sainio P, et al. (2010) Handgrip strength cut points to screen older persons at risk for mobility limitation. J Am Geriatr Soc 58: 1721-1726.

26. Wilson PW, D'Agostino RB, Levy D, Belanger AM, Silbershatz H, et al. (1998) Prediction of coronary heart disease using risk factor categories. Circulation 97: 1837-1847.

27. Islam FM, Wu J, Jansson J, Wilson DP (2012) Relative risk of cardiovascular disease among people living with HIV: a systematic review and meta-analysis. HIV Med 13: 453-468.

28. Freiberg MS, Chang CC, Kuller LH, Skanderson M, Lowy E, et al. (2013) HIV infection and the risk of acute myocardial infarction. JAMA Intern Med 173: 614-622.

29. Marsh AP, Rejeski WJ, Espeland MA, Miller ME, Church TS, et al. (2011) Muscle strength and $\mathrm{BMI}$ as predictors of major mobility disability in the Lifestyle Interventions and Independence for Elders pilot (LIFE-P). J Gerontol A Biol Sci Med Sci 66: 1376-1383.

30. Wang CY, Chen LY (2010) Grip strength in older adults: test-retest reliability and cutoff for subjective weakness of using the hands in heavy tasks. Arch Phys Med Rehabil 91: 1747-1751.

31. Bedimo RJ, McGinnis KA, Dunlap M, Rodriguez-Barradas MC, Justice AC (2009) Incidence of non-AIDS-defining malignancies in HIV-infected versus noninfected patients in the HAART era: impact of immunosuppression. J Acquir Immune Defic Syndr 52: 203-208.

32. Bonnet $F$, Chêne G (2008) Evolving epidemiology of malignancies in HIV. Curr Opin Oncol 20: 534-540.

33. Lanoy E, Spano JP, Bonnet F, Guiguet M, Boué F, et al. (2011) The spectrum of malignancies in HIV-infected patients in 2006 in France: the ONCOVIH study. Int J Cancer 129: 467-475.

34. Lenfant C, Chobanian AV, Jones DW, Roccella EJ (2003) Seventh report of the Joint National Committee on the Prevention, Detection, Evaluation, and Treatment of High Blood Pressure (JNC 7): resetting the hypertension sails. Hypertension 41: 1178-1179. 